\title{
ARMILLARIA ROOT ROT IN ONTARIO ${ }^{1}$ By J. H. HUNTLY ${ }^{2}$, J. D. CAFLEY ${ }^{3}$, and E. JORGENSEN ${ }^{4}$ $A B S T R A C T$
}

The occurrence and importance of Armillaria root rot in plantations is discussed. It is concluded that this fungus may become of greater economic importance in Ontario as reforestation makes increasing use of cut-over land. Experiments have been established to investigate the possibilities of control through girdling of trees in preparation of the planting site, as suggested by the findings of Leach (1937). It is recommended that practicing foresters follow the development of Armillaria root rot in areas where silviculture is practiced. Information collected in this way may be of use in the evaluation of the biological impact of silvicultural practices as well as in the development of Armillaria root rot control methods.

The fungus, Armillaria mellea (Vahl) Quél., has a world-wide distribution on many hosts. Its general characteristics and the symptoms of the disease which it causes as a facultative parasite are well known (Boyce 1948) and need no description here, beyond a mention of the mode of infection.

The fungus can live as a saprophyte on the stumps or roots of dead trees, and the basidiospores from the gills of the fruiting bodies are windborne to infect stumps or roots of freshly cut, but rarely living, trees. (Leach 1937, Reitsma 1932). Normally, infection of living trees takes place through mycelial transfer at contact points with an infected root. The healthy cork layer of the host is penetrated by hyphae arising from rhizomorphs growing out from the food source in which the fungus is established. No wounds or dead roots need be present (Day 1929, Patton \& Riker 1959).

However, the presence of $A$. mellea does not necessarily result in disease. The susceptibility of the host is determined by its physiological condition, which in turn is influenced by the environment. Resistance to infection is largely dependent on the degree to which soil conditions favor tree and fungus growth. The fungus becomes a serious pathogen under moisture or fertility conditions adverse to tree growth. Under extreme soil moisture conditions, the tree may be reduced to a low state of vigor in which it is unable to resist subsequent infection. Armillaria mellea requires humid conditions for optimum growth, but may develop under adverse conditions due to the protection against desiccation afforded by its rhizomorphs. The fungus may thus survive occasional droughts which place the host tree in a condition which is highly susceptible to the development of disease.

${ }^{1}$ Contribution No. 766 from the Forest Entomology and Pathology Branch, Department of Forestry, Ottawa, Canada.

${ }^{2}$ Born in Dunbar, Scotland. B.Sc. (Forestry) 1957 from the University of Edinburgh; Master of Forestry 1960 from the University of British Columbia. In June, 1960, appointed Research Officer in charge of plantation diseases in Ontario at the Laboratory of Forest Pathology, Southern Research Station, Maple, Ontario.

${ }^{3}$ Laboratory of Forest Pathology, Southern Research Station, Maple, Ontario. Biographical reference in Forestry Chronicle 34: 57. 1958.

- Formerly Laboratory of Forest Pathology, Southern Research Station, Maple, Ontario; now Assistant Professor (Forest Pathology), Faculty of Forestry, University of Toronto, Toronto, Ontario. Biographical reference in Forestry Chronicle 32: 87. 1956. 
All evidence indicates that the fungus is always secondary to some other factor which predisposes the tree to disease. The site, the choice of species, the method of regeneration, the type of thinning, defoliation, and suppression, may all have such an influence (Day 1929, Thomas 1934).

A systematic survey of the occurrence of $A$. mellea in coniferous plantations in Ontario has not been undertaken. However, the Laboratory of Forest Pathology at Maple, Ontario, has, during the past 12 years studied a number of Armillaria attacks throughout the Province.

These limited investigations have fully confirmed the above evaluation of $A$. mellea as a pathogenic fungus. Armillaria attacks have not been recorded from plantations except where stumps were present. Further, disease severity has been found to vary considerably with site, plantation age and species, and with the size and species of the stumps. Economically serious attacks of Armillaria root rot over large areas have not yet been recorded from Ontario plantations. This is not because there are no plantations of low vigor for there are plenty of these, but rather because to date most plantations have been established on abandoned farm land, where there are no dead stumps or roots to serve as a food base for the fungus.

However, where $A$. mellea locally has found a suitable food base, and host tree vigor has been reduced by some environmental factor, considerable tree killing has been caused by the disease in the vicinity of the stumps.

Such a condition exists in a plantation of red pine, Pinus resinosa Ait., established in 1942 close to the village of Wyevale in the Wildman County Forest. In this stand the initial infection of $A$. mellea was present in several hardwood stumps. By 1956, of 99 trees planted in the immediate vicinity of the stumps only 34 were recorded as healthy, 35 has disappeared, 28 were killed by $A$. mellea, and 2 were severely attacked. By 1960,8 more trees had died, and an additional tree was severely attacked by Armillaria mellea.

The development of the disease in these trees may be partly attributed to a loss of vigor due to site or to suppression by adjacent mature maples. The remainder of the plantation, where hardwood stumps are absent, was recorded "healthy" in 1956. However, the fungus is gradually creating a more extensive infection centre, and trees are now being killed outside the original plot area. These trees are not suppressed but are in places obliged to compete for available soil moisture with advance maple growth, a factor which may have been critical on this sandy site during the dry summer of 1958, when the growing season rainfall was 7 inches below average.

In contrast to this area, an outbreak of $A$. mellea in a plantation at Midhurst had not spread beyond the original infection. This stand was planted as second generation red pine in 1951, replacing a previous stand of this species destroyed by Ips pini Say in 1949 and 1950. In 1956, of the 798 trees planted, 13 had disappeared, 726 were healthy, and 59 had died from attack of $A$. mellea (Fig. 1). Since that date the trees have apparently become less susceptible and none have been killed since 1959.

In order to study the spread of $A$. mellea in coniferous plantations, sample plots were established in areas of Uxbridge Forest where infections of the fungus were present in old hardwood stumps. The pattern of spread of the fungus in a typical sample plot is illustrated by Figures 2, 3, and 4. 
The plantation in which this plot was established is made up of alternate rows of red pine and white pine (Pinus strobus L.), now 31 years old. The odd-numbered rows are red pine and the even numbered white pine.

Figure 2 illustrates the situation in 1950, when the first examination was made. By this date the original infection of $A$. mellea had spread radially from the hardwood stumps and roots to infect 27 of the 93 trees present in the plot. By 1960 spread of the fungus had extended to all limits of the plot, and a total of 51 trees was severely infected.

The radial spread of infection has been more evident among the white pine, which have become suppressed and of low vitality due to competition with red pine. The vigorous red pine have been more successful in resisting infections, and the disease has only appeared in individuals reduced in health through suppression by neighboring trees.

The occurrence of $A$. mellea is widespread in Ontario as evidenced by the large number of fruiting bodies that annually are found in natural forest stands; Armillaria in the late fall often is the most common of the forest mushrooms.

Judging from the general distribution of the fungus and from plantation experiences, of which only a minor part has been presented here, it may be expected that Armillaria root rot will become of greater economic importance in Ontario as reforestation makes increasing use of cut-over land. The abundant development of rhizomorphs that occur after the felling of infected broadleaved trees exposes the next crop to infection. Further, it is to be expected that young seedlings of conifers, at least for some time following planting, are in a susceptible physiological condition to Armillaria root rot, even when planted on a proper site. The latter may be of particular interest where second generation plantations are to be established.

In consequence it appears that practical methods for the control of Armillaria root rot will be required where cut-over land is planted in Ontario. Stump removal will hardly be economically feasible over large areas, but fortunately the rhizomorph behavior of the fungus suggests a possible control method.

It has been found (Garrett 1953) that the production of rhizomorphs in pure culture is dependent on a certain threshold nutrient status of the substrate. On a low nutrient agar medium more rhizomorphs are formed than are able to develop, this fact being attributed in part to an exhaustion of nutrients by the original mycelium. The nutrient supply has therefore an important bearing on the proportion of successful infections through rhizomorphs. The infection potential decreases with decreasing size of food base and with an increase in the distance between the food base and the host.

Leach (1937 and 1939) working in tea plantations in Nyasaland has shown that $A$. mellea will develop sparingly on stumps or roots depleted of carbohydrate reserves, a condition which can be achieved by girdling the trees one to two years before they are cut. Although Armillaria may on occasion appear after girdling, the resulting disease is reduced considerably.

The efficiency of girdling as a control method is at present under investigation in Ontario. Controlled experiments were established in 1958, over a 
range of sites, and involving various broad-leaved tree species. Felling of the girdled and control plots was carried out in September, 1960, and the areas were planted in the spring of 1961. Survival and growth studies in relation to the possible development of Armillaria mellea will then be carried out. It is hoped that these studies will provide information regarding the behavior of $A$. mellea under conditions existing in southern Ontario.

Girdling as a control method may not necessarily provide for the complete control of Armillaria root rot in plantations on cut-over land in Ontario. However, it is hoped that the method may provide a degree of control which is sufficient for practical purposes. Should this not be the case, a method developed for the control of root rots in rubber plantations in Malaya (Napper 1932) may be applied in addition to the girdling. Diseased seedlings are used as indicators of points in plantations where infected root material from the previous stand constitutes an inoculum. The infected seedlings along with the source of infection are removed and replanting can then safely be done. Such a scheme requires continued inspection of the plantations in the first year following planting and a thorough knowledge of the symptoms of disease in the different tree species.

Planting of less susceptible tree species is a control method that should be considered for high-hazard areas. However, information on relative host susceptibility is not available at present and is not readily obtainable without an elaborate system of field experiments. An evaluation of physiological "tree vigor" at periods through the growing season on different sites could be of key interest in this connection. Unfortunately, the forest pathologist at present lacks the tools necessary for such a study and the choice of tree species as well as the management of infected stands will therefore have to depend mainly on local silvicultural experience. It may therefore be in order to recommend that practicing foresters continuously follow the development of Armillaria root rot within their areas. These observations on different host susceptibilities following silvicultural treatment, or between sites, may provide an indirect evaluation of silvicultural practices as well as information of importance in the development of Armillaria root rot control practices.

\section{REFERENCES}

BOYCE, J. S. 1948. Forest pathology. McGraw-Hill Book Company, Inc., New York.

BUCKLAND, D. C. 1953. Observacions on Armillara mellea in immature Douglas fir. Forestry Chronicle 29: 344-346.

DAY, W. R. 1927. Parasitism of Armillaria mella in relation to conifers. Quarterly Jour. of Forestry: 9-2 [.

DAY, W. R. 1929. Environment and disease. A discussion on the parasitism of Armillaria mcllat. Forestry 3: 94-103.

GARRETT, S. D. 1938. Soil conditions and the root infecting fungi. Biol. Rev, Cambridge Phil. Soc, 13: 159-185.

GARRETT, S. D. 1951. Ecological groups of soil fungi: a survey of subscrace relacionships. New Phytologist 50: 149-166.

GARRETT, S. D. 1953. Rhizomorph bchaviour in Armillaria mellea (Vahl) Quél. I. Faccors controlling rhizomorph initiation by $A$. mellad in pure culture. Ann. Botany London 17: $63-79$.

GARRETT, S. D. 1956. Rhizomorph behaviour in Armillaria mollo' (Vahl) Qućl. II. Logiscics of infection. Ann. Botany London 20: 193-209.

LEACH, R. 1937. Observations on the parasicism and control of Armillaria melled. Proc. Roy. Soc. B. 121: $561-573$. 
LEACH, R. 1939. Biological control of Armillariu mollit. Trans. Br. Mycol. Soc, 23: 320-329. NAPPER, R. P. N. 1932. Fomes lignosus. J. Rubber Res. Inst. Malaya: 4-38.

PATTON, R. F. and A. J. RIKER. Artificinl inoculations of pine and spruce trees with Armillaria mell'ri. Phytopathology. 49: 615-622.

RAYNER, M. C. 1930. Observations on Armillaria mellew in pure eulture with certain conifers. Forestry 4: 65-77.

REITSMA, J. 19j2. Seudicn über Armillaria mellea. Phytopath. Z. 4: 461-522.

THOMAS, H. E. 1929. Studies on the nature of host resistance to Armillaria mellea. Phytoparthology 19: 1140 .

THOMAS, H. 1:. 1934. Studies on Armillario mellea, infection, parasitism, and host resistance. J. Agr. Research 48: 187-218.

VAN VLOTEN, H. 1936. Onderzoekingen over Armillaria meller Fungus, Wageningen 8: 20-23. (Abstr. in Rev. Appl. Mycol, 16: 215. 1937).

WEBSTER, C. C., WIEHE, P. O. and C. SMEE. 1950. The cultivation of the Tung oil tree (Alcurites montana) in Nyasaland. Nyas. Agr. Quart. Jour. 9(1):40-41.

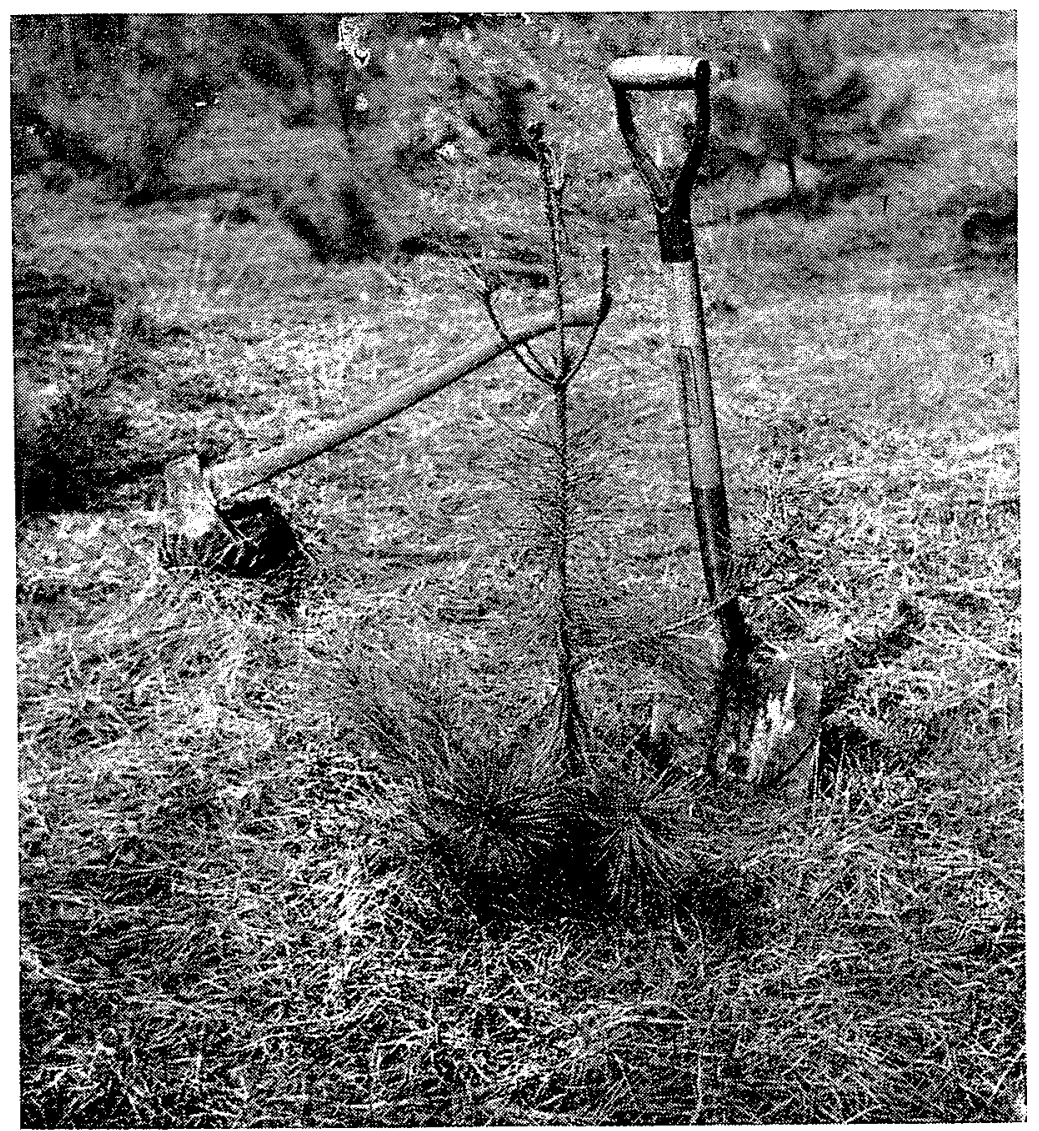

FIGURE 1. Red pine severely attacked by Armillaria mellea which has advanced through roots of a nearby stump. (Photo, Midhurst, 1956). 
Figures for Page 224
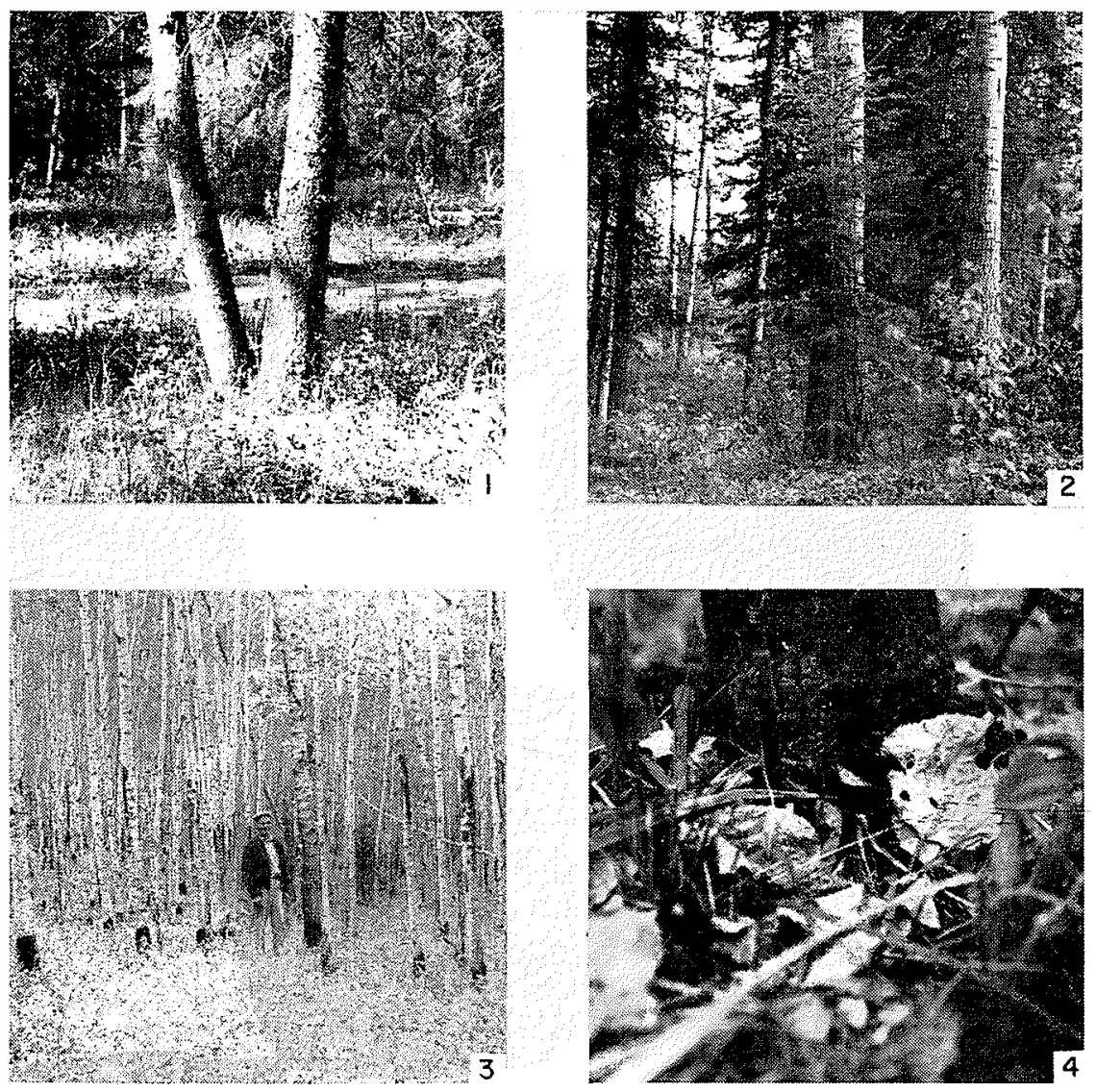

FIGURE 1. "Twinned" white spruce and trembling aspen.

FIGURE 2. A white spruce sapling occurring naturally at the base (north side) of a mature aspen.

FIGURE 3. General view of the 40-year-old dense aspen stand (Stand 1).

FIGURE 4. A four-year-old white spruce seedling at the base (north side) of an aspen (Stand 1). 
Figures for Page 229 follow

FIGURES 2, 3 and 4. Patterns of spread of the fungus in a typical sample plot 1950, 1956, and 1960 .

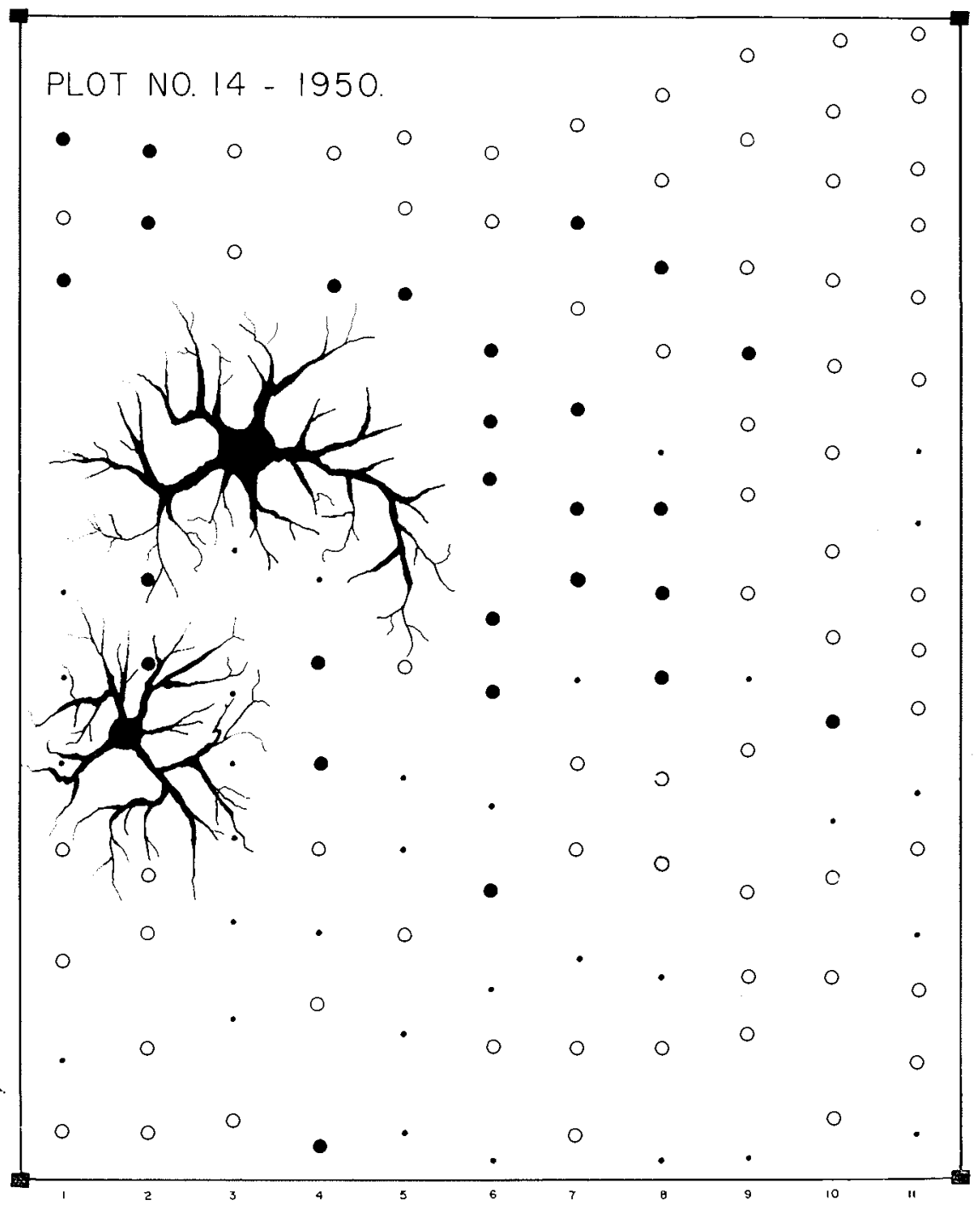




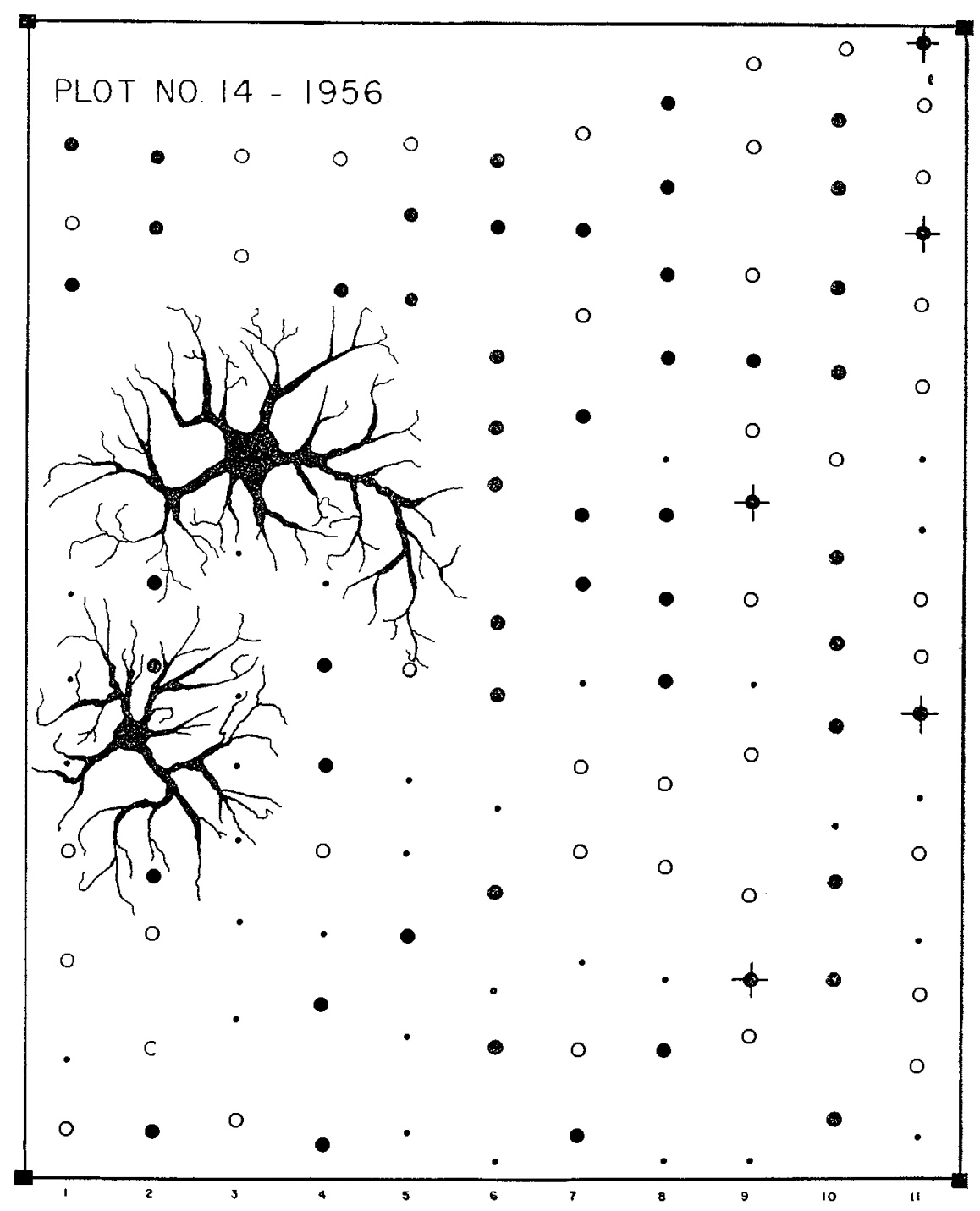




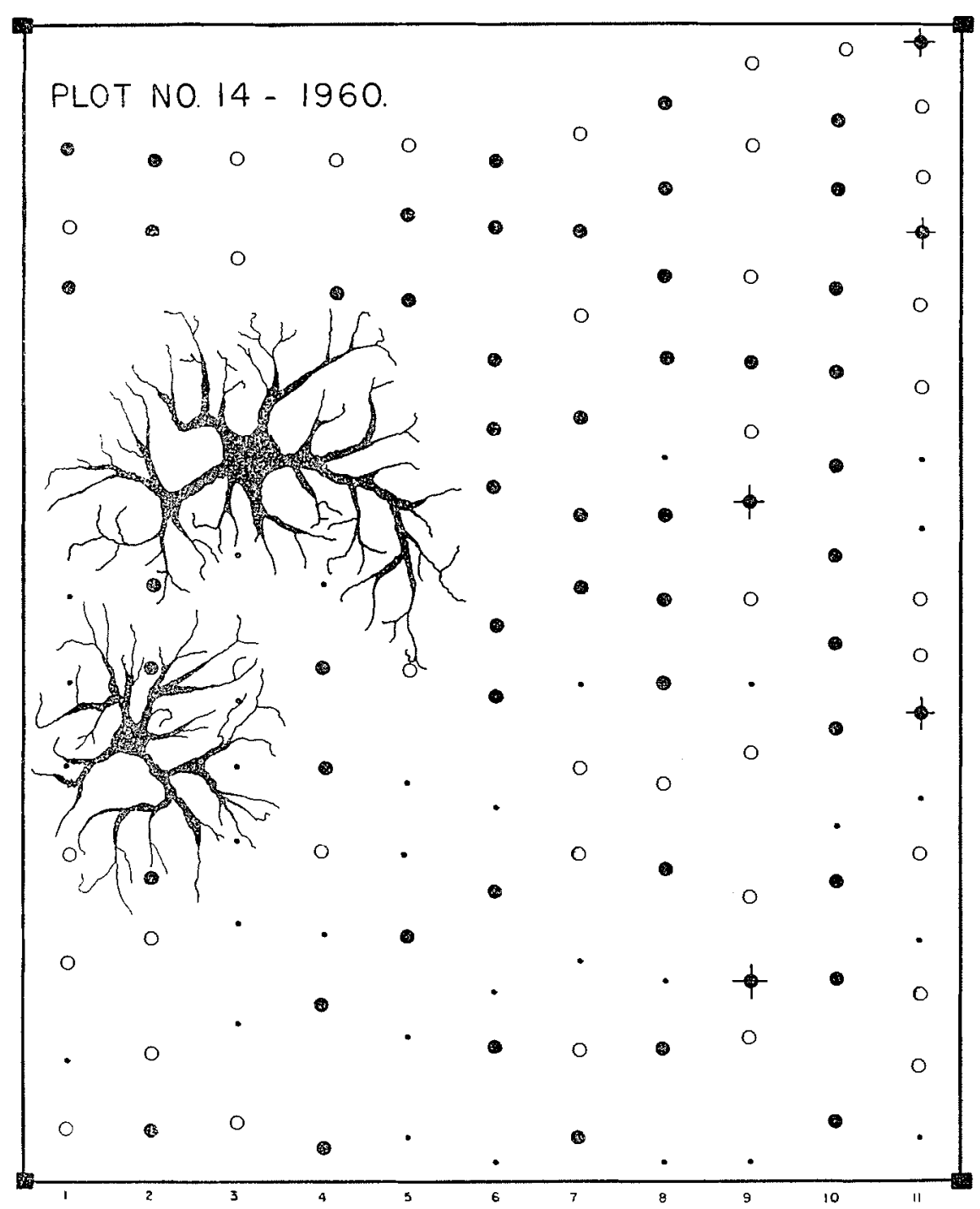

